\title{
SOCIAL AND ECONOMIC EXCHANGES WITH THE ORGANIZATION AND EMPLOYEE WORK OUTCOMES: A STUDY IN TURKISH WORK CONTEXT
}

\author{
DOI: 10.17261/Pressacademia.2020.1319 \\ RJBM- V.7-ISS.4-2020(2) -p.213-227
}

\section{Nurdan Ozaralli}

Marmara University, Faculty of Economics and Administrative Sciences, Istanbul, Turkey. nozaralli@marmara.edu.tr, ORCID: 0000-0002-5927-8256

Date Received: October 27, 2020

Date Accepted: December 5, 2020

To cite this document

Ozaralli, N. (2020). Social and economic exchanges with the organization and employee work outcomes: a study in Turkish work context. Research Journal of Business and Management (RJBM), V.7(4), p.213-227.

Permanent link to this document: http://doi.org/10.17261/Pressacademia.2020.1319

Copyright: Published by PressAcademia and limited licensed re-use rights only.

\section{ABSTRACT}

Purpose - Social Exchange Theory is one of the most influential concepts in organizational behavior literature. It provides a wide comprehension upon exchange dynamics both at an interpersonal and organizational level. This study presents and tests a framework that links the two different forms of employee-organization exchange, namely social exchange and economic exchange with important employee outcomes- affective commitment, in-role behavior, extra-role behavior and turnover intention.

Methodology - The study was conducted in the province of Istanbul/Turkey, based on convenient sample of 195 participants from private organizations. Participants were contacted through snowball sampling technique via the researcher's personal and professional contacts.

For testing the hypotheses of the present study, simple regression and multiple regression analyses were utilized. Data obtained from the participants were analyzed through SPSS 22.

Findings- . Results indicated that social exchange is positively related with affective commitment, in-role behavior, extra-role behavior and negatively related with turnover intention. On the other hand, economic exchange was found to be negatively related with affective commitment and turnover intention while positively related with in-role behavior. Economic exchange did not significantly predict extra-role behavior. This study has provided partly inconsistent results found in similar studies conducted in the Western work settings.

Conclusion- The findings of the present research in the Turkish work settings seems to draw the attention to a need for further detailed studies on the specific relationships between social and economic exchange and important employee work outcomes. Theoretical and practical implications are also discussed.

Keywords: Social-economic exchanges, commitment, extra-in role behavior, turnover

JEL Codes: B30, 031, M14

\section{INTRODUCTION}

The relationship between employees and the organizations has been the subject of continuous research. EmployeeOrganization Relationship (EOR) has often been described as critical for eliciting important employee work attitudes and behaviors (Coyle-Shapiro \& Conway, 2004). Shore et al., (2006) describes the relationship between an employee and the organization as an exchange relationship and classifies them as social exchanges (relationships based on socio-emotional aspects and trust) and economic exchanges (relationships based on financial aspects). A foundation of the EOR literature is that 'employees develop exchanges for socio-emotional and economic reasons, and that the type of exchange relationship can predict employee motivation, attitudes and behaviour in relation to the employer' (Kuvaas \& Dysvik, 2009, 3500).

Exchange relationships are not unidirectional but rather reciprocal. Social Exchange Theory (SET), with its emphasis on the felt obligation to reciprocate, can explain why workers are motivated to contribute on behalf of their organizations (Walumbwa, et al., 2011). Since the parties present their resources to each other, they expect some of their needs to be met by the other. Specifically, an employee who is satisfied by what he has received provides more contributions to his organization in comparison with one who is less satisfied by his gatherings. As a result, these dynamics directly affect employee and organizational outcomes. 
Numerous studies have been conducted on social and economic exchange and several variables have been shown to be associated with these two concepts. Research has suggested that social and economic exchanges are distinct and relate differently to organizational antecedents such as perceived leadership style and organizational culture (Song et al., 2009), organizational climate (Kuvaas et al., 2008), perceived organizational support (Rhoades \& Eisenberger, 2002), and employment relationship (Wang et al., 2003; Hom et al., 2009) and outcomes such as job satisfaction (Gakovic \& Tetrick, 2003), commitment (Hom et al., 2009), work effort and organizational citizenship behaviors (Kuvaas et al., 2008), performance and relative absence and tardiness (Shore et al., 2006). Such studies have produced empirical results consistent with the predictions of social exchange theory. These studies have found that employees act on the norm of reciprocity and return favorable organizational treatment with positive attitudes and high levels of performance. Affective commitment, which refers to the employee's emotional attachment to the organization, is one of the concepts that can be related with social and economic exchanges between the employees and the organization. As earlier research mostly focused on performance in general, this study will also contribute to earlier research by investigating the direct effects of social and economic exchanges on both perceived in-role and extra-role performance behaviors based on the categorizations of Katz \& Kahn (1966). The differentiation between in-role and extra-role performance behaviors will contribute to our knowledge about the antecedents of these two aspects of performance. Finally, the (intention to) turnover which is a considerable issue for all organizations will be investigated in connection with the two antecedents - namely social and economic exchanges between the employees and the organization.

Shore et al., (2009a) argue that social and economic exchange elements of the employee-organization relationship are different and that employees in organizations perceive both social and economic exchange elements to exist concurrently with varying degrees. However, Cropanzano \& Mitchell (2005) claimed that most studies have focused on social exchange in the employee-organization relationship with very little empirical research on economic exchange. They also argued that "further investigations of how exchange orientation influences organizational relationships is of great importance (p.878)".

Song et al., (2009) explicitly called for more research that examines the role of social exchange relationships in explaining employee attitudes and behaviors in different cultural settings. Although past research has documented social and economic exchange and their relationship with employee attitudes and behaviors, little is actually known about whether the relationships between employee-organization exchanges and employee reactions extend beyond United States-based samples.

SET has been used as a basis and an analytical lens to explain many organizational attitudes and behaviors such as Leader Member Exchange (LMX), employee performance, organizational citizenship behavior, trust, perceived organizationalsupervisory support, organizational justice... both in Western societies and in Turkey. However, research on the focus point of SET namely, social and economic exchanges between employees and the organization appears to be extremely limited in the Turkish work context. In an effort to address this gap in the literature, we will investigate the two distinct elements of SET -social and economic exchange- within employee-organization relationship in connection with important work-related attitudes and behaviors, namely affective commitment, in-role behaviors, extra-role behaviors and intention to turnover. Following, we will review literature on social and economic exchange and the proposed organizational outcomes.

In the following sections, we will first review work that supports the distinction between social and economic exchanges in employee-organization relationship, along with related organizational outcomes. The hypotheses of the study will be formulated upon the theoretical background. Then information on sampling, data collection and measures are given. The analyses and results are presented in the following sections. Lastly, the findings are discussed and the implications along with limitations and suggestions for future work are provided.

\section{THEORETICAL BACKGROUND}

\subsection{Social and Economic Exchange in Employee-Organization Relationship}

Based on SET (Blau, 1964), exchange relationships have an extensive theoretical background in the relevant literature. Prior research has used social exchange theory to explain the relationship between LMX and effective work attitudes and behaviors (e.g. Wayne, Shore, \& Liden, 1997). From a more macro perspective, the exchange relationships between employees and their organizations has also been widely studied (e.g. Shore, et al., 2006).

Employee-organization exchange relationships may be represented by both social employee-organization exchange and economic employee-organization exchange relationships. In other words, the relationship between employees and their organizations has both social and economic components. Blau (1964) argues that employees tend to develop exchanges for socio-emotional (e.g., give and take, being taken care of by the organization), as well as for economic reasons (e.g., pay and benefits). There are major distinctions between social and economic exchange relationships. The basic distinction is: social 
exchanges generate socio-emotional responses such as gratitude, trust, obligation and so forth, while economic exchange are based merely on economic transactions (Hackett et al., 2003).

In particular, social exchange can be defined as deliberate actions that are performed by individuals or groups with the expectation that other party will act in a similar fashion (Blau, 1964; Foa \& Foa, 1980). Individuals who receive favors will have a tendency to reciprocate with resources that are favorable to the other party, and vice versa. In other words, when an individual does another party a favor, there is an expectation of some future return. However, when the favor will be reciprocated, and in what form, is often unclear. In other words, social exchanges entail unspecified, rather complex obligations and thus, depend on mutual trust (Blau, 1964). Since the reciprocation is not guaranteed by a written agreement, trust is developed through continuous interactions in social exchange relationships, and both parties must prove their credibility to one another (Cole et al., 2002). Interactions are not all about what parties have received in a short period of time. In other words, the focus is not merely on the concrete gatherings that each party receives. Instead, both parties try to develop a long lasting, satisfactory relationship with possible further interactions that might be beneficial for each (Song, et al., 2009). Besides, as the social exchange is ongoing and based on feelings of obligation, it requires a long-term or openended orientation and investment in the relationship (Blau, 1964).

Studies have shown that social exchange relationship has variety of organizational outcomes. For one thing, social exchange is correlated with work performance. Individuals who developed a social exchange relationship with their organizations are shown to have higher work performance (Shore \& Tetrick, 1991). In addition, social exchange is associated with higher organizational citizenship behavior (Gakovic \& Tetrick, 2003), implying that individuals who have higher levels of social exchange perception demonstrate increased organizational citizenship behavior. Apart from these, social exchange is related with job satisfaction, too. Specifically, individuals who have social exchange relationship with their organizations are more satisfied with their jobs (Kuvaas et al., 2008).

Economic exchanges, however, are rather impersonal and trust is not a necessity for the relationship to be sustained. Economic agreements or contracts specify narrowly defined financial obligations and expected actions for the parties (e.g., pay for performance). Based on the agreement between interacting parties, some sanctions are identified for the party that do not obey the agreement or behave opportunistically (Cropanzano \& Mitchell, 2005). In economic exchanges, transactions include relatively short-term and financially-oriented relationships. Interactions are based on the exchange of well-identified commodities and services (Podsakoff et al., 2000). Both parties focus on merely meeting their responsibilities and increase their short-term gatherings, as much as possible. For this reason, economic exchange relationships are usually time-bound and close-ended (Shore et al., 2006).

Relevant literature has also provided significant associations between economic exchange and several organizational outcomes. Specifically, economic exchange relationship is negatively associated with organization citizenship behavior, implying that in a purely economic exchange employees are not motivated to make further contribution to their organizations. Specifically, the more dominant economic exchange is, the less individuals demonstrate citizenship behaviors in their organizations (Song, et al., 2009; Zhu, 2016). In addition, economic exchange is negatively correlated with work performance, demonstrating that work performance drops in a purely economic exchange (Kuvaas et al., 2012). Apart from those variables, economic exchange is closely related with intention to quit. In other words, employees are more willing to leave their organizations if their economic exchange perception is heightened (Hom et al., 2009).

\subsection{Social and Economic Exchange, Work Attitudes and Behaviors}

From an organizational perspective, interdependence among the employees as highlighted in Social Exchange Theory establishes mutual obligations that create a need to reciprocate the resources received from the other party. For instance, in the typical employment relationship, the organization provide tangible and intangible resources such as compensation in the form of money and fringe benefits, job security, training as well as care, support or consideration. In return, employees also provide some resources such as time, expertise, or effort. This interdependency between employees and their organization gradually creates a sense of commitment and loyalty to the organization (Henderson et al., 2008). A foundation of the employee-organization relationship is based on the notion that "employees develop exchanges for socio-emotional and economic reasons, and that the type of exchange relationship can predict employee motivation, attitudes and behaviour in relation to the employer" (Kuvaas \& Dysvik, 2009, 3500).

\subsubsection{Affective Commitment}

Employee-Organization relationship has been recognized as a social exchange relationship in many studies and organizational commitment is considered as a behavior developed as social exchange relationship is established (Liu \& Deng, 2011). 
Employees who have social exchange relationships with their organizations are more likely to feel obliged to return their gatherings with more particularistic resources, such as commitment towards their organizations (Song, et al., 2009).

Organizational commitment relates to the strength of one's identification with and involvement in a particular organization (Lyons et al., 2006) and is a valuable component of organizational effectiveness. Relevant literature has demonstrated that organizational commitment represents feelings of involvement, reciprocity and responsibility towards one's organization.

Drawing on the early works and questioning the appropriateness of the unidimensional constructs on both conceptual and empirical grounds, Allen \& Meyer (1990) proposed a three-dimensional conceptualization of organizational commitment. Affective commitment is the emotional bonding of an employee towards his/her organization. Normative commitment refers to the sense of responsibility and obligation to continue employment in the current organization. Continuance commitment refers to the recognition of the costs associated with leaving the organization and the perception of the lack of job alternatives. Concerning their three-component model of organizational commitment, Meyer \& Allen (1991) claimed that work experiences have the strongest and most consistent positive relationship with affective commitment. Affective commitment refers to the employee's emotional attachment to, identification with, and involvement with the organization (Allen \& Meyer, 1990). Therefore, the present study discusses affective commitment as one of the focus points as it has been shown that this dimension has a positive effect on permanent work behaviors (Jin et al., 2010).

Individuals who have social exchange relationships with their organizations are likely to have attachment and identification with their organizations. As affective commitment means a powerful emotional attachment to an organization, it is regarded as the result of high-quality reciprocity between employees and their organization (Colquitt et al., 2007). For this reason, social exchange element would motivate them to have more involvement and embeddedness towards the organization that they are working for. As social exchange emphasizes the socioemotional (e.g., give and take, being taken care of by the organization) aspects of exchange, we might conclude that it is positively related with affective commitment which is rooted in the norms of reciprocity. When employees are positively treated by their organization, they develop positive feelings toward that organization, which leads to high levels of affectve commitment.

Thus, we hypothesize that

H1a: Social exchange is positively related with affective commitment.

In contrast, economic exchange is characterized by a low level of trust and relationship investment (Blau, 1964). Its focus is on narrow financial obligations (e.g., pay and benefits) without any long-term investments in the employee (e.g., employment security or career planning). An economic exchange does not emphasize socio-emotional outcomes, but rather includes shorttermed, financially-oriented relationships. In a purely economic exchange relationship, we expect subordinates to be less psychologically and emotionally involved and consequently, less likely to develop affective commitment towards their organization.

Thus, we hypothesize that

H1b: Economic exchange is negatively related with affective commitment.

\subsubsection{In-Role and Extra-Role Performance Behaviors}

This research includes the two aspects of performance- namely in-role performance and extra-role performance behaviors. Organ (1990) suggested a distinction between in-role (task) performance and extra-role (contextual) performance behaviors and added that they were both theoretically and practically important because they were determined by different antecedents.

In-role behaviors were initially described by Katz and Kahn (1966) as those behaviors that are prescribed as being part of one's job, and are recognized by the organization's formal reward systems. In-role performance includes behaviors required by explicit job descriptions and refers to the duties and responsibilities one executes as part of his/her job assignments (Vigoda, 2000). Williams \& Anderson (1991) and Goodman \& Svyantek (1999) defined in-role behaviors as task performance that contributes directly to the technical core of the organization, such as working a full 8-hours a day, or completing all required task assignments.

Extra-role behaviors, however, are rather discretionary behaviors that go beyond existing role expectations. Organ $(1988,4)$ defined extra-role behavior as "individual behavior that is discretionary, not directly or explicitly recognized by the formal reward system, and, in the aggregate, promotes the efficient and effective functioning of the organization". 
When organizations create an environment where employees develop a favourable social exchange relationship based on trust and socioemotional elements, they would feel obliged to return this favour by investing more time and energy in their in-role tasks that contribute to the organizational outcomes. This would strengthen their expectation that greater efforts will be awarded by the organization. It has been shown that employees who experience more positive emotions would perform better (Fredrickson \& Losada, 2005). In a similar study, Orpen (1994) found out that employees who receive organizational support will put more effort in their work and will perform better than employees who do not have support from their organizations.

Organ (1990) argued that SET was the best theoretical explanation for employee citizenship behavior. When employees feel that they have a positive social exchange relationship with the organization, their socio-emotional needs would be fullfilled and their well-being would be enhanced. Hence, they are more likely to reciprocate favorable organizational treatment with positive work behaviors and go "above and beyond" the specified task requirements. Higher levels of organizational trust and investment associated with high-quality social exchange relationships create feelings of employee obligation and well-being, which, in turn, motivate employees to show behaviors that exceed the formal task requirements. It might be the case that strong social employee-organization exchange would enhance the employees' both in- and extra-role work performance through increased feelings of obligation, well-being and loyalty.

Thus, we hypothesize that

$\mathrm{H} 2 \mathrm{a}$ : Social exchange is positively related with in-role behaviors.

$\mathrm{H} 2 \mathrm{~b}$ : Social exchange is positively related with extra-role behaviors.

Economic exchange with its financial emphasis and well-defined obligations might also encourage employee behavior that meets organizational expectations for in-role job performance. Even in a rather impersonal economic relationship with their organization, employees feel obliged to do what the job requires to be paid for their work effort. In response to the perception of an economic exchange with no long-term orientation and mutual interests, employees would still reciprocate by acceptable levels of performance but they would be unwilling to contribute much to the organization above and beyond required task performance. Economic exchanges are likely to be associated with meeting job requirements through acceptable, rather than superior, levels of performance, suggesting that economic exchange may be less associated than social exchange with job performance. That is, the financial aspects of exchange serve to encourage behavior that meets, rather than exceeds, organizational expectations for employee job performance. Shore et al. $(2006,846)$, considering the contractual nature of economic exchange, did not hypothesize a relationship between economic exchange perception and contexual performance because it was expected to "... encourage behavior that meets, rather than exceeds, organizational expectations for employee job performance." We question this view and argue that with weak psychological engagement due to the low level of mutual trust and socio-emotional involvement, employees would hesitate to exceed expectations for extra-role job performance and step forward as organizational citizens.

Thus, we hypothesize that

H3a: Economic exchange is positively related with in-role behaviors.

$\mathrm{H} 3 \mathrm{~b}$ : Economic exchange is negatively related with extra-role behaviors.

\subsubsection{Turnover Intention}

Prior research has evidenced that turnover has been a serious issue for all organizations. Lambert \& Hogan $(2009,97)$ claim that "the level of turnover is an important indicator of the effectiveness and efficiency of an organization". Turnover intention has been considered to be the main and immediate predictor of actual turnover. Turnover intention can be defined as "an individual's subjective probability that he/she is permanently leaving the employer in the near future and captured the last in a series of withdrawal cognitions that also included thoughts about quitting and the search for alternative employment (Tepper, et al., 2009, 157). It has been a major challenge for organizations to retain their workforce as high turnover rates can be expensive for companies, compromising firm profitability due to continually wasting resources on recruiting, retraining and re-skilling applicants.

There has been a wide literature on turnover intention as it has connections with various individual and organizational issues. Employees may voluntarily leave organizations for a variety of reasons, including low satisfaction with their jobs and/or employers, low organizational commitment, disapproval of organizational justice, limited promotion and growth opportunities, a better opportunity elsewhere, a low quality of work life etc... 
Thus, the final focus of the present study was to investigate the impact of employee-organization exhange relationship on turnover intention. Van Knippenberg et al. (2007) state that employees are likely to leave their organizations because they are dissatisfied with the exchange relationship (e.g., poor organizational support, contract violations, etc.). Macnall et al., (2010) claim that individuals with positive emotions about their work experiences have lower turnover intentions. Positive actions directed at employees by the organization would contribute to the establishment of high-quality, long-term exchange relationships, compelling employees to repay advantageous treatment received from their employers. More specifically, emplyees within a strong social exchange relationship based on relational trust and investment with long-term orientation would have lower intentions to leave the organization.

Thus, we hypothesize that

H4a: Social exchange is negatively related with turnover intention.

Economic exchanges, on the other hand, are associated with "easy exit". As economic exchanges are typically based on lower levels of mutual trust and relationship investment with an emphasis on financial and tangible resources, they involve rather shaky interactions. Since this type of exchange does not imply a long-term investment or ongoing relationship, interacting parties focus merely on what they received and they rarely take into consideration who provides the resources. Either party can terminate the exchange as soon as they find a better alternative that can provide the desired resource (Shore et al., 2009b). This suggests that when economic exchange is high, employees may display higher levels of turnover intentions.

Thus, we hypothesize that

$\mathrm{H} 4 \mathrm{~b}$ : Economic exchange is positively related with turnover intention.

\section{METHOD}

\subsection{Sample and Data Collection}

The population of this study were white-collar employees who work at the private sector in Istanbul, Turkey. Since it is impossible to reach all of them, a representative sample was chosen based on convenience sampling. Participants were contacted through snowball sampling technique via the researcher's personal and professional contacts. Employees were sent e-mails and instructed via social media to click on a website link to complete the online research instrument. Respondents were assured of confidentiality. In order not to limit the study to one industry only, various industries in the private sector were included in the study. The majority of the respondents were from banking, finance and IT sectors. Survey data were collected during November-December 2019. Participants were asked to answer questions regarding demographic information (age, gender, tenure, education), their exchanges with the organization, and questions about their work attitudes and behaviors. Out of 250, 195 of the employees returned the surveys. Finally, data obtained from the participants were analyzed through SPSS 22

\subsection{Demographic Characteristics}

In terms of demographic findings, $49 \%$ of respondents were females, and the remaining $51 \%$ were males. The respondents were relatively young, aged between 22 and 35 years of age. The total tenure of the respondents was 7.2 years and their current tenure was 5.06 years. The respondents can be argued to be highly educated. $69 \%$ of the respondents were holding bachelor degree and $20 \%$ of them have postgraduate degree, and the remaining $11 \%$ were high school graduates.

\subsection{Measures}

Social and Economic Exchange relationship of participants with their organizations was measured using Shore et al. (2006)'s Social and Economic Exchange Scale (SEES). The items were translated into Turkish by the authors and back translated into English by experienced professors and checked for consistency with the original. The SEES composed of 17 items measuring the two sub-dimensions; eight social exchange items (e.g., "My relationship with my organization is based on mutual trust") and nine economic exchange items (e.g., "My relationship with my organization is strictly an economic one - I work and they pay me").

Affective Commitment was measured by the seven-item affective commitment scale developed by Meyer et al., (1993). A sample item is, "I would be very happy to spend the rest of my career with this organization". In-role and extra-role performance was measured by Goodman \& Svyantek's (1999) sixteen-item scale. The researchers based their instrument on Smith et al.,'s (1983) organizational citizenship behavior measure. This scale covers the two forms of perceived job performance namely, in-role (task) performance and extra-role (contextual performance). In-role performance behavior was assessed with nine items, including "You perform well in the overall job by carrying out tasks as expected". Extra-role 
performance was measured by seven items. The instrument includes extra-role performance behaviors directed towards the organization and towards the fellow employees. Sample items are, "You willingly attend functions not required by the organization, but help in its overall image", and "You take initiative to orient new employees to the department even though not part of your job description". Employees rated their in-role and extra-role performance behaviors based on their selfrating. The turnover intention was measured by a 3-item scale developed by Cammann, et al., (1979). A sample item is "I often think of leaving the organization". The demographic section of the questionnaire asked questions about the participants' age, gender, educational level, and organizational tenure. Participants' gender was dummy coded, 0 for female and 1 for male. The educational level of the participants was measured in categories: (1) high school, (2) bachelor's degree, (3) post-graduate degree. The age and the organizational tenure were measured by open-ended questions.

\section{RESULTS}

Before testing the hypotheses, we conducted a series of principal component factor analyses using varimax rotation for both scales separately. The 17 -item SEES yielded two factors explaining $63.69 \%$ of the total variance. One item that loaded on both factors (There is a lot of give and take in my relationship with [my organization]) and one item which had a loading less than .50 (I only want to do more for [my organization] when I see that they will do more for me) was excluded from the analysis. Thus, the first factor that consisted of seven items was called social exchange and the second factor consisting of eight items was called economic exchange (Table 1). The Cronbach alpha estimates for the two scales were .85 and .89 , respectively.

Table 1: Factor analyses of Social and Economic Exchange Scale

FACTOR 1: Social Exchange (\% Var: 31,869)

Factor loadings

I don't mind working hard today - I know I will eventually be rewarded by [my organization]

My relationship with [my organization] is based on mutual trust.

I try to look out for the best interest of [the organization] because I can rely on my organization to take care of $\quad .804$ me.

Even though I may not always receive the recognition from [my organization] I deserve, I know my efforts will be rewarded in the future.

[My organization] has made a significant investment in me.

The things I do on the job today will benefit my standing in [this organization] in the long run.

I worry that all my efforts on behalf of [my organization] will never be rewarded. [R]

FACTOR 2: Economic Exchange (\% Var: 31,824)

My relationship with [my organization] is impersonal - I have little emotional involvement at work. 896 I do what [my organization] requires, simply because they pay me.

I watch very carefully what I get from [my organization], relative to what I contribute.

Total variance explained: 63,69

Kaiser-Meyer-Olkin Measure of Sampling Adequacy: 0.613; df: 78

Bartlett significance value: 0.000 ; Approx. Chi-Square: 1423.583

The principal component analysis for the 16 item In-role/Extra-role performance scale yielded two factors explaining $67.07 \%$ of the total variance. The Cronbach's alpha reliability coefficient for the first factor representing In-role performance behaviors was .93, for the second factor representing Extra-role performance behaviors was .91. Affective commitment and Turnover intention scales each yielded to a single factor, with Cronbach's alpha reliability coefficients .92 and .89 , respectively. It seems that all Cronbach's alpha reliability coefficients are high enough to conclude that the scales are highly reliable "good" measures. 
Table 2 reports the descriptive statistics, scale reliabilities, and bivariate correlations. In general, the correlations reflect preliminary answers for the expected relations and provide confidence that the measures functioned properly for the effects tested in this study.

Table 2: Means, Standard Deviations, Intercorrelations and Alphas for the Variables

\begin{tabular}{|c|c|c|c|c|c|c|c|c|}
\hline Variables & M & SD & 1 & 2 & 3 & 4 & 5 & 6 \\
\hline 1. Social Exch. & 3.71 & 1.01 & $(.85)$ & & & & & \\
\hline 2. Economic Exch. & 3.55 & 1.23 & $-.19^{*}$ & (.89) & & & & \\
\hline 3. Affective Commit. & 3.50 & 1.18 & $.54^{* *}$ & $-.36^{* *}$ & (.92) & & & \\
\hline 4. In-role Perf. B. & 4.05 & 1.01 & $.35^{* *}$ & $.27^{* *}$ & $.37^{* *}$ & (.93) & & \\
\hline 5. Extra-role Perf. B. & 3.75 & 1.15 & $.37^{* *}$ & $-.20^{*}$ & $.39^{* *}$ & $.28^{* *}$ & $(.91)$ & \\
\hline 6.Turnover Intention & 3.05 & 1.02 & $-.44^{* *}$ & $-.23^{*}$ & $-.32^{* *}$ & $-.28^{* *}$ & -.15 & (.89) \\
\hline
\end{tabular}

** Significant at $\mathrm{p}<0.0 \mathrm{l}, *$ Significant at $\mathrm{p}<0.05,2$-tailed

Internal consistency alphas are in parenthesis along the diagonal.

The means for the social and economic exchange are above the theoretical midpoint (3.5) of the scales. In fact, employees express a slightly higher level of social exchange (3.71) with their organization than economic exchange (3.55). Affective commitment score (3.50) is at the midpoint. The mean score for in-role performance behavior (4.05) is the highest, indicating most respondents think they are doing good at their job. Extra-role performance behavior (3.75) is also above the avarage. The lowest score is turnover intention (3.05). It seems that most respondents have low intention to leave their organization.

The significant correlations were generally in the expected directions as predicted in hypotheses. A review of the correlation matrix indicates that social exchange showed moderate positive significant relationships with affective commitment $(r=.54$, $p<.01)$, in-role performance $(r=.35, p<.01)$, extra-role performance $(r=.37, p<.01)$, but it had a negative significant relationship with turnover intention $(r=-.44, p<.01)$. The economic exchange had low-to-moderate negative significant relationships with affective commitment $(r=-.36, p<.01)$, extra-role performance $(r=-.20, p<.05)$ and turnover intention $(r=-.23, p<.05)$, but a positive significant relationship with in-role performance $(r=.27, p<.01)$. The correlations indicated that especially the existence of social exchange is likely to increase employees' perceived affective commitment, perceived in-role performance and extra-role performance, while decreasing their intention to leave the organization.

While the correlations suggest initial support for the hypotheses, multiple regression analyses were performed to evaluate the relative contribution of each type of exchange relationship to the prediction of affective commitment, in-role performance, extra-role performance, and turnover intentions (Table 3).

Table 3: Multiple Regression Analysis

\begin{tabular}{lcccc}
\hline & $\begin{array}{c}\text { Affective } \\
\text { commitment }\end{array}$ & $\begin{array}{c}\text { In-role } \\
\text { performance }\end{array}$ & $\begin{array}{c}\text { Extra-role } \\
\text { performance }\end{array}$ & $\begin{array}{c}\text { Turnover } \\
\text { intention }\end{array}$ \\
\hline Social exchange & $.51^{* *}$ & $.32^{* *}$ & $.34^{* *}$ & $-.41^{* *}$ \\
\hline Economic exchange & $-.33^{* *}$ & $.24^{* *}$ & -.17 & $-.20^{*}$ \\
\hline Adj. $\mathrm{R}^{2}$ & $.381^{* *}$ & $.263^{* *}$ & $.246^{* *}$ & $.324^{* *}$ \\
\hline $\mathrm{F}$ & $28.85^{* *}$ & $25.16^{* *}$ & $24.32^{* *}$ & $26.11^{* *}$ \\
\hline${ }_{p}<.05 ; * * p<001$ & & &
\end{tabular}

Note: We also conducted multiple regression analyses with demographic variables before adding Social exchange and Economic exchange variables. The pattern of results obtained from these analyses did not differ substantially from that of the results reported here.

Table 3 presents the contributions of social exchange and economic exchange perception on each outcome attitude and behavior. Regression results support most of the findings from the zero-order correlations. As can be followed, social exchange and economic exchange perception together explain 38.1 percent of the variance of affective commitment (Adj. $R^{2}$ $=.381, \mathrm{~F}=28.85, \mathrm{p}<.001)$. The positive, significant contribution of social exchange to affective commitment $(\beta=.51, p<.001)$ indicates that employees' social exchange perception is an important predictor of affective commitment to the organization. The beta coefficient for economic exchange was also significant $(\beta=-.33, p<001)$, indicating a negative impact of economic exchange on affective commitment. It seems that the higher the employees' economic exchange perception, the lower their affective commitment to the organization. Thus, our hypotheses $\mathrm{H} 1 \mathrm{a}$ and $\mathrm{H} 1 \mathrm{~b}$ are supported. Similarly, social exchange and 
economic exchange perception together explain 26.3 percent of the variance of perceived in-role performance (Adj. $R^{2}=.263$, $\mathrm{F}=25.16, \mathrm{p}<.001)$.

The beta coefficient for social exchange and in-role performance was significant $(\beta=.32, p<.001)$ indicating a positive contribution of social exchange perception to in-role performance. The beta coefficient for economic exchange and in-role performance was also significant $(\beta=.24, p<.001)$, indicating a positive contribution of economic exchange perception to inrole performance. Thus, our hypotheses $\mathrm{H} 2 \mathrm{a}$ and $\mathrm{H} 3 \mathrm{a}$ are also supported. It seems that both social and economic exchange perceptions make positive contributions to employees' in-role performance. Again, the variances of extra-role performance are explained together by social exchange and economic exchange perception (Adj. $R^{2}=.246, F=24.32, p<.001$ ). However, the beta coefficients show that the variances of extra-role performance are significantly predicted by only social exchange perceptions $(\beta=.34, p<.001)$, whereas economic exchange failed to do so $(\beta=.17, n s)$. According to the results of correlation analysis, economic exchange is in a significant and negative relationship with extra-role performance; but when it has been regressed together with social exchange perception, it appeared to have no significant contribution to extra-role performance. It seems that social exchange perception is the only variable that can explain the variances of extra-role performance. Thus while $\mathrm{H} 2 \mathrm{~b}$ is supported, $\mathrm{H} 3 \mathrm{~b}$ is rejected.

Finally, results indicate that variances of turnover intention is significantly predicted by both social exchange and economic exchange perceptions (Adj. $R^{2}=.324^{* *}, F=26.11, p<.001$ ). The beta coefficient for social exchange $(\beta=--.41, p<.001)$ indicates a negative relationship between social exchange and turnover intention. Thus, $\mathrm{H} 4 \mathrm{a}$ is supported. It seems that as social exchange perception increases, employees are less willing to quit their jobs. However, the beta coefficient for economic exchange $(\beta=-.20, p<.05)$ also indicated a significant negative impact of economic exchange to turnover intention. Contrary to our hypotheses, $\mathrm{H} 4 \mathrm{~b}$ is rejected. It seems that higher levels of economic exchange were associated with lower levels of turnover intention.

All in all, the present data point to social exchange as the type of exchange relationship that more strongly influences employee attitudes and behaviors.

\section{DISCUSSION}

In order to shed some light on the issue of emploee-organization exchanges in a culturally different work setting, we mainly aimed to explore the relative impact of social and economic exchanges on employee work attitudes and behaviors.

We empirically aimed to investigate these relationships by using Social Exchange and Economic Exchange concepts as two separate constructs rather than two opposite ends of the same continuum. A review of the correlation matrix (Table 1) indicates that economic exchange is relatively weakly correlated with social exchange $(r=-.19$ and $p<.05)$. This is an important contribution as it supports the previous research indicating that social and economic exchange should rather be conceptualized as two distinct concepts (Shore et al., 2006; Buch et al, 2011).

With regards to the other simple correlations, social exchange showed moderate positive significant relationships with affective commitment, in-role performance, extra-role performance, but it had a negative significant relationship with turnover intention. When social and economic exchange are regressed together (Table 3 ), the results supported the predicted main effects that social exchange is likely to have on four criteria variables. Not surprisingly, we found that social exchange perceptions make a significant positive contribution on employees' affective commitment to the organization, which is consistent with the results of Walumbwa et al.'s (2011) and Kuvaas et al.'s (2012) research. This means that social exchanges that include more socio-emotional responses characterized by feelings of gratitude, mutual trust, caring and obligation to reciprocate positively affect the degree to which employees feel emotionally attached to their organization.

As was previously discussed, social exchange involves emotional reciprocity and a series of interactions between two parties that generate obligations to each other. In line with findings by Wayne et al. (2002), we found support to conclude that employees with strong social exchange relationships with their organization are more likely to exhibit behaviors that are supportive of organizational goals, put more effort in their work and perform better. It seems that in a work setting where organizations make investments on the employees, trust and take care of them, the employees feel obliged to return this favor by investing more time and energy in their tasks.

The same link of reasoning can be applied with regard to extra-role performance. Prior research suggest that social exchange relationships are associated not only with higher levels of in-role job performance but organizational citizenship behaviors as well (Shore et al., 2006; Kuvaas \& Dysvik (2009). Our results also show that high levels of social exchange are associated with high levels of extra-role behaviours. It seems that a strong social exchange relationship creates employees' energy to go 
beyond their formal job responsibilities that benefit the organization. Employees are likely to feel the obligation to return favorable actions with behaviors that include "good deeds" directed towards their peers and the organization.

Performance is a multidimensional and complex construct. The rather low-to-medium yet significant relationships between social exchange and in-role and extra-role performance can be explained by the fact that performance can be predicted by factors consisting of a mix of personality traits, job characteristics and sociopsychological environment of the organization. Among these factors, we focused in the present study only on the social and economic exchanges, two important elements of the employee-organization relationship.

As to turnover intention, we found that employees who develop social exchange relationship with their organizations are less willing to quit their current jobs. Prior research (Hom et al., 2009; Cole et al., 2002) also suggest that social exchange with socioemotional components of mutual obligation and investment with long-term orientation lower employee intentions to leave the organization. In fact, employees might be afraid of losing their positions in their organizations where they have emotional attachment. Karagonlar et al., (2015) found that in a Turkish sample social exchange would reduce turnover intention through work engagement primarily for employees with low self efficacy. Supporting evidence also comes from the strong predictive validity of affective commitment in relation to turnover intentions and actual turnover (Meyer \& Herscovitch, 2001).

All in all, when employees had stronger social exchanges they demonstrated more positive attitudes and behaviors. More specifically, in all four cases the relationships between social exchange and the criterion measures were consistent with prior research, further highlighting the importance and strength of social relationships in the workplace.

As Cropanzano \& Mitchell (2005) also claimed, most research has focused on social exchange in the employee-organization relationship with very little empirical research on economic exchange. Thus, in the study we investigated the relationship between economic exchange and four criteria variables. In economic exchange, having an emotionally-fulfilling relationship is not the main priority for interacting parties. From an organizational point of view, employees are rather driven towards maximizing their material gatherings and view the relationship on a purely economic basis (Podsakoff et al., 2000). To our expectation, results have revealed a moderately negative correlation between economic exchange and affective commitment, suggesting that individuals who are dominantly economic exchange-oriented show little, if any, emotional attachment towards their organizations.

Economic exchanges may not emphasize socio-emotional outcomes but are characterized by the exchange of goods and services that have values which are separate from their sentimental values for the interacting parties. The emphasis is on narrow, well-defined contractual obligations; defining what needs to be accomplished and how performance is rewarded (e.g., pay for performance). To support our expectation, we found a positive relationship between economic exchange and in-role performance, implying that employees have to show the required performance in order to repay the transactional obligations in a "quid pro quo" manner. Our findings are partially in alignment with prior research. As Kamdar \& Van Dyne (2007) claim that economic exchanges associated with a narrowing of job roles would encompass only required performance, Shore et al. (2006) found that, because of its contractual nature, relationships characterized by economic exchanges can be unrelated to work performance.

Following the same line of reasoning, we expected that employees whose relationships with the organization are predominantly based on economic exchanges would not be willing to go "over and beyond" the expected level of performance. As the simple correlation analysis showed a significant and negative relationship with economic exchange and extra-role performance, when it has been regressed together with social exchange, it showed a non-significant relationship, indicating no support for our assumption. It seems that the contractual, narrowly-defined nature of economic exchanges are not predictive of extra-role performance which is associated with discretionary behaviors. This finding is in alignment with past research by Shore et al. $(2006,846)$ who did not hypothesize a relationship between economic exchange perception and extra-role work performance because it was expected to "... encourage behavior that meets, rather than exceeds, organizational expectations for employee job performance."

Considering the low levels of relationship investment and short-term tit-for-tat exchanges of mostly economic resources, we assumed that economic exchange will be positively related with turnover intention. To the contrary of our assumptions, our results revealed that economic exchange is relatively weakly, yet negatively related with turnover intention. It seems that employees who have developed an economic exchange relationship with their organizations may rationally define the financial obligations and the exchange of well-defined benefits (e.g., pay for performance) and have no reason not to keep their status quo. In other words as long as the terms of the economic exchange are fulfilled, employees' intention to quit their jobs decreases. 


\section{CONCLUSION}

In recent years, organizational scholars (e.g. Cropanzano \& Mitchell, 2005; Shore, et al., 2009b; Song, et al., 2009) explicitly called for further research that investigates the role of social exchange relationships in explaining employee attitudes and behaviors in different cultural settings. As a response to calls for further research, we conducted the present study to investigate the role of social exchanges within a non-US context. Turkey has a culture that differentiates from other Western countries such as the United States where most research on SET has been conducted. Thus, we aimed to report empirical results from a Turkish sample to see if SET and the norm of reciprocity function any similar to what has been reported in other mostly US-based studies.

First of all, the results of this study brought evidence to the proposition that there are two relatively independent aspects of exchange in the employee-organization relationship, namely social and economic exchange. It is evident that employees encounter both kinds of exchanges concurrently with varying degrees. Also, the results suggest that these two forms of exchange can operate relatively independently, exhibiting differential relations with affective commitment, job performance, and turnover intention. Thus, it is useful to explicitly measure employees' social and economic exchange perceptions with their organizations in order to better understand the nature of exchanges.

In general, the present study generally supported the findings of relevant literature. Most particularly, our pattern of results also showed that social exchange has stronger and more positive effects than economic exchange. We can conclude that organizations should consistently seek ways to create a climate with stronger social exchange perceptions among their employees. They should focus on the socioemotional aspects of their relationship by treating their employees well, developing mutual trust, and making investment in them. This would create a social organizational climate characterized by trust, cooperation, and long-term orientation which, in turn, leads to beneficial employee attitudes and behaviors. As the social exchange literature explicitly posits, the formation of trust develops as the social relationships evolve. Thus, organizations should train organizational members in interpersonal skills to facilitate the development of high-quality exchange relationships.

The results of the present study showed that economic exchange has more limited effects, at least in relation to the particular outcomes studied. Our results on economic exchange perceptions have received mixed support from prior research. The positive relationship of economic exchange with in-role performance and the negative relationship with turnover intention contradicts with earlier research by Shore et al., (2009a). However, the present research has been conducted in a culturally different setting. Our results can also be explained by the economic conditions of Turkey and the high rate of unemployment among young people. It might be the case that employees do a rational (not necessarily emotional) "cost-benefit" evaluation of occupational interaction based on maximization of material profits. This might encourage them to do what the job requires to be paid for their work effort and keep their membership with the organization as long as they are paid for their work effort.

We can bring support to our findings on economic exchange-turnover intention relationship from the continuance commitment literature, as well. Meyer \& Allen (1991) define continuance commitment as an awareness of the costs associated with leaving the organization. Evolved from Becker's (1960) side-bet theory, continuance commitment posits that employees' association with the organization is based on a calculative assessment of economic benefits gained. Organizational members maintain membership with their organization because of the positive extrinsic rewards obtained through the effort-reward bargain as well as the scarcity of alternative employment opportunities elsewhere. Taing et al., (2011) made a distinction between positive and negative side of continuance commitment and specified dimensions based on the perception of "beneficial economic exchanges" versus the perception of "low job alternatives". They found that continuance commitment based on economic exchanges was related favorably to work outcomes, such as task performance and citizenship behaviors, while continuance commitment based on low job alternatives was related unfavorably to such outcomes. Thus, organizations should foster continuance commitment based on economic exchanges by increasing employee awareness of the benefits available to them and by providing social support to employees who feel they "have to" remain in the organization.

Our results suggested that employees pursue the satisfaction of both social and economic needs. As Goodwin et al., (2009, 973) also argued, "The instrumental and social aspects of the relationship appear to exist simultaneously". However, economic exchanges have received considerably less attention in the social exchange research literature (Cropanzano \& Mitchell, 2005). Economic exchanges may not involve affect or provide intrinsic motivation, but what is common to both types of exchanges is reciprocation, that is, the contributor's expectation of some form of future return (Blau, 1964). Contrary to more recent research (e.g. Kuvaas \& Dysvik, 2009; Song, et al., 2009), our findings support the traditional views which claim both social and economic exchanges in general motivate productive work behavior (e.g. Rhoades \& Eisenberger, 2002). It might as well be possible that the extrinsic motivation of employees with a strong economic exchange perception could 
produce acceptable levels of performance under certain circumstances or in some cultural contexts. For example, Meyer et al., (2002) argue that pay satisfaction is positively related to positive work attitudes and behaviour. In a related vein, the "payfor-performance" literature suggest that the instrumental performance-outcome relationship influences performance quantity and increases performance depending on task characteristics (Weibel et al., 2010), which we were not able to control for in the present study.

In short, our findings reveal that social and economic exchange are both to be emphasized in organizations. As shown in the present study, economic exchange associated with poor work outcomes (low affective commitment and low extra-role behavior) highlights the importance of attending to this aspect of employee-organization relationship. On the other hand, providing employees with "a fair day's pay for a fair day's work" may relate positively to employees' justice perceptions, forming a baseline which create conditions that will promote social exchange relationships in the workplace.

In short, it should be kept in mind that social and economic exchanges exist side-by-side in organisations. Employees' main motives in their associations with organizations may be tied to economic outcomes, however, they are also involved in social interactions with their peers and superiors. Viewed in this light, organizations need to enhance the emotional or intrinsic aspects of relationships in economic exchange environments so that both employees and their organizations can pursue economic and social objectives.

\section{LIMITATIONS AND SUGGESTIONS FOR FUTURE WORK}

This study includes some limitations. First of all, data were collected by the convenience sampling technique from employees working in the private sector located in Istanbul, the largest city of Turkey. Thus, we should be cautious in generalizing the results for all types of organizations, sectors or the overall country. However, in an attempt to make the findings more generalizable than studies where data were collected from one organization only, we tried to distribute the respondents across a number of industries and organizations. Yet, due to the limited sample size, future research with larger sample size is needed before we can draw any firmer conclusions. Another limitation of the study is that we relied exclusively on selfreport measures that often lead to common method bias which is regarded as a source of measurement error. To reduce this concern to a certain extent, respondents were informed that participation is voluntary and fully anonymous. Besides, it should be noted that the relationships found in this study are correlational and not causal. The reciprocal nature of the social and economic exchanges between parties and the cross-sectional design of this study does not permit examination of the causal linkages; this remains for future research.

There seems to be a number of unaddressed issues in social exchange research related to cultural issues. Culture is a system of values that affects all human perceptions and behaviors and thus, is expected to influence the underlying principles of social exchanges. Aydın (2017) in her theoretical work envisages that individuals high in uncertainty avoidance and power distance would have a low inclination for social exchanges as social exchanges involve uncertainty and risk due to the diffuse, open-ended obligations. She further proposes that individuals high in collectivism would have a high inclination for social exchanges. Turkish culture displays a collectivist structure, also measuring high on power distance and high uncertainty avoiding (Hofstede, 1980). The norm of reciprocity might be universal, however, from a culture-specific perspective additional research is needed that investigates how individual employees respond to social and economic exchanges with their employers. For example, for one employee social exchange can be a sign of support from the organization, while for another employee this type of employment relationship with open-ended obligations and a long-term reciprocity orientation can involve greater personal risk. Thus, future research on the relationships between social and economic exchanges and work outcomes should include other potential moderators and mediators. This would help scholars and organizational leaders to better understand the meaning of exchange relationships across individuals and cultural contexts.

Empirical work should be extended to explore what it means to have social and economic exchanges with one's organization across different cultures. Our study seems to give clues to the impact of economic exchanges in contexts where it has more positive implications than observed in Western studies. In line with this implication, it is important to identify the conditions under which economic employee-organization relationships would be as effective as the social exchanges. Thus, it may be interesting to investigate the extent to which the economic aspects can be a part of a high-quality employee-organization relationship. We also suggest enhancing social and economic exchange scales to include the actual resources provided by the organization in relation to economic as well as social exchanges.

Despite its limitations, this paper contributes to past research on social exchange theory and employee-organization relationship by reporting empirical results from a Turkish sample. Our study highlights the value of examining both social and economic exchange elements of the employee-organization relationship. It also provides support for the proposition that social exchange theory is applicable within a Turkish context and the norm of reciprocity as cited by social exchange theory is a key factor in social exchanges. With respect to practical implications, an understanding of the complexity and dynamics 
of exchange perceptions within employee-organization relationship may help organizational leaders better manage expectations to the benefit of both employees and the organization.

\section{REFERENCES}

Allen, N. J., and Meyer, J. P. (1990). The measurement and antecedents of affective, continuance, and normative commitment to the organization. Journal of Occupational Psychology, 63:1-18.

Aydın. E. (2017). Social Exchange in the context of culture: A Theoretical Study. International Journal of Economic and Administrative Studies (IJEAS), (Kültür bağlamında sosyal mübadele: Kuramsal bir çalışma. Uluslararası Iktisadi ve Idari Incelemeler Dergisi, UiiiD), 16. UiK Özel sayısı, 547-562.

Becker, H. S. (1960). Notes on the concept of commitment. American Journal of Sociology, 66: 32-40.

Blau, P. (1964). Exchange and Power in Social Life, Wiley, New York, NY.

Buch, R., Kuuvas, B., and Dysvik, A. (2011). The measurement and outcomes of economic leader-member exchange relationships. Paper presented at the Annual Meeting of the Academy of Management, San Antonio.

Cammann, C., Fichman, M., Jenkins, D. and Klesh, J. (1979). The Michigan Organizational Assessment Questionnaire. Unpublished Manuscript, University of Michigan, Ann Arbor, MI.

Cole, M. S., Schaninger, Jr., W. S., and Harris, S. G. (2002). The workplace social exchange network: A multilevel, conceptual examination. Group and Organization Management, 27(1): 142-167.

Colquitt, J.A., Scott, B.A., and LePine, J.A. (2007). Trust, trustworthiness, and trust propensity: A meta-analytic test of their unique relationships with risk-taking and job performance. Journal of Applied Psychology, 92: 909-927.

Coyle-Shapiro, J.A.M., Shore, L.M., Taylor, M.S. and Tetrick, L.E. (2004). The Employment Relationship: Examining Psychological and Contextual Perspectives, Oxford University Press, Oxford.

Cropanzano, R. and Mitchell, M. S. (2005). Social exchange theory: An interdisciplinary review. Journal of Management, 31(6): 874-900.

Foa, U. G., and Foa, E. B. (1980). Resource theory: Interpersonal behavior as exchange. In K. J. Gergen \& M. S. Greenberg \& R. H. Willis (Eds.), Social exchange: Advances in theory and research. New York: Plenum.

Fredrickson, B. L., and Losada, M. F. (2005). Positive Affect and the Complex Dynamics of Human Flourishing. American Psychologist, 60: 678686.

Gakovic, A., and Tetrick, L.E. (2003). Perceived organizational support and work status: a comparison of the employment relationships of part-time and full-time employees attending university classes. Journal of Organizational Behavior, 24: 649-66.

Goodman, S. A., and Svyantek, D. J. (1999). Person-organization fit and contextual performance: Do values matter. Journal of Vocational Behavior, 55(2): 254-275.

Goodwin, V. L., Bowler, W. M., and Whittington, J. L. (2009). A social network perspective on LMX relationships: Accounting for the instrumental value of leader and follower networks. Journal of Management, 35(4): 954-980.

Hackett, R. D., Farh, J., Song, L. J., and Lapierre, L. M. (2003. LMX and Organizational Citizenship Behavior: Examining the links within and across Western and Chinese samples. G. B. Graen (Ed.). Dealing with Diversity: A Volume in: LMX Leadership: The Series, (pp.219-264). Greenwich, CT: Information Age Publishing.

Henderson, D. J., Wayne, S. J., Shore, L. M., Bommer, W. H., and Tetrick, L. E. (2008). Leader-member exchange, differentiation, and psychological contract fulfillment: A multilevel examination. Journal of Applied Psychology, 93(6): 1208-1219.

Hofstede, G. (1980). Culture's consequences: International differences in work-related values. Sage: Newbury Park, CA.

Hom, P. W., Tsui, A. S., Wu, J. B., Lee, T. W., Zhang, A. Y., Fu, P. P., and Li, L. (2009). Explaining employment relationships with social exchange and job embeddedness. Journal of Applied Psychology, 94: 277-297.

Jin, X. L., Lee, M.K.O., and Cheung, C.M. K. (2010). Predicting continuance in online communities: Model development and empirical test. Behavior and Information Technology, 29(4): 383-394.

Kamdar, D. and Van Dyne, L. (2007). The joint effects of personality and workplace social exchange relationships in predicting task performance and citizenship performance. Journal of Applied Psychology, 92(5): 1286-1298.

Karagonlar, G., Öztürk, E. B. and Özmen, Ö.N.T. (2015). Social exchange with the organization and turnover intention: The roles of self efficacy and work engagement (Çalışanın örgütle sosyal mübadele algısı ve işten ayrılma niyeti: İşe cezbolmanın ve öz yeterliliğin rolü). ODTÜ Gelişme Dergisi, 42 (December-Aralık), 411-433.

Katz, D. and Kahn, R. L. (1966). The social psychology of organizations. John Wiley \& Sons, Inc., New York. 
Kuvaas, B. and Dysvik, A. (2009). Perceived investment in permanent employee development and social and economic exchange perceptions among temporary employees. Journal of Applied Social Psychology, 39(10): 2499-2524.

Kuvaas, B., Arnulf, J.K., and Dysvik, A. (2008). Social and economic exchange perceptions and intrinsic motivation among knowledge workers. Academy of Management Conference, Anaheim, CA.

Kuvaas, B., Buch, R., Dysvik, A. and Haerem, T. (2012). Economic and social leader-member exchange relationships and follower performance. The Leadership Quarterly, 23(5): 756-765.

Lambert, E., and Hogan, N. (2009). The importance of job satisfaction and organizational commitment in shaping turnover intent: A test of a causal model. Criminal Justice Review, 34: 96-118.

Liu, X., and Deng, J. (2011). Development of organizational commitment based on the social exchange theory. Paper presented at the International Conference on Management and Service Science (MASS), 1-6.

Lyons, S. T., Duxbury, L. E., and Higgins, C. A. (2006). A Comparison of the Values and Commitment of Private Sector, Public Sector, and Parapublic Sector Employees. Public Administration Review, 66(4): 605-618.

McNall, L.A., Nicklin, J.M., and Masuda, A.D. (2010). A meta-analytic review of the consequences associated with work-family enrichment. The Journal of Business and Psychology, 25(3): 381-396.

Meyer, J. P. and Allen, N. J. (1991). A three-component conceptualization of organizational commitment. Human Resource Management Review, 1(1): 61-89.

Meyer J. P., Allen, N. J., and Smith, C. (1993). Commitment to organizations and occupations: Extension and test of a three-component conceptualization. Journal of Applied Psychology, 78: 538-551.

Meyer, J.P. and Herscovitch, L. (2001). Commitment in the workplace: toward a general model. Human Resource Management Review, 11(3): 299-326.

Meyer, J.P., Stanley, D.J., Herscovitch, L. and Topolnytsky, L. (2002). Affective, continuance, andnormative commitment to the organization: a meta-analysis of antecedents, correlates, andconsequences, Journal of Vocational Behavior, 61(1), 20-52.

Organ, D. W.(1988). Organizational citizenship behavior: The good soldier syndrome. Lexington, United Kingdom: Lexington Books/DC Heath and Com.

Organ, D. W. (1990). The motivational basis of organizational citizenship behavior. In B. M. Staw \& L. L. Cummings (Eds.), Research in organizational behavior, 12: 43-72. Greenwich, CT: JAI Press.

Orpen, C. (1994). The effects of organizational and individual career management on career success. International Journal of Manpower, 15(1): $27-37$

Podsakoff, P. M., MacKenzie, S. B., Paine, J. B., and Bachrach, D. G. (2000). Organizational citizenship behaviors: A critical review of the theoretical and empirical literature and suggestions for future research. Journal of Management, 26: 513-563.

Rhoades, L. and Eisenberger, R. (2002). Perceived organizational support, a review of the literature. Journal of Applied Psychology, 87: 698714.

Shore, L. M., Bommer, W. H., Rao, A. N., and Seo, J. (2009a). Social and economic exchange in the employee-organization relationship: the moderating role of reciprocation wariness. Journal of Managerial Psychology, 24(8): 701- 721

Shore, L. M., Coyle-Shapiro, J., Chen, X., and Tetrick, L. (2009b). Social exchange in work settings: Content, process, and mixed models. Management and Organization Review, 5(3): 289-302.

Shore, L. M., and Tetrick, L. E. (1991). A construct validity study of the survey of perceived organizational support. Journal of Applied Psychology, 76: 637-643.

Shore, L. M., Tetrick, L.E., Lynch, P., and Barksdale, K. (2006). Social and economic exchange, construct development and validation. Journal of Applied Social Psychology, 36: 837-867.

Smith, C. A., Organ, D. W., and Near, J. P. (1983). Organizational citizenship behavior: Its nature and antecedents. Journal of Applied Psychology, 68: 655-663.

Song, L.J., Tsui, A.S. and Law, K.S. (2009). Unpacking employee responses to organizational exchange mechanisms: the role of social and economic exchange perceptions. Journal of Management, 35: 56-93.

Taing, M. U., Groff, K. W., Granger, B. P., Jackson, E. M., and Johnson, R. E. (2011). The multidimensional nature of continuance commitment: Commitment owing to economic exchanges versus lack of employment alternatives. Journal of Business and Psychology, 26: $269-284$. 
Tepper, B. J., Carr, J. C., Breaux, D. M., Geider, S., Hu, C. and Hu, W. (2009). Abusive supervision, intentions to quit, and employees' workplace deviance: A power/dependence analysis. Organizational Behavior and Human Decision Processes, 109: 156-167.

Van Knippenberg, D., van Dick, R., and Tavares, S. (2007). Social identity and social exchange: Identification, support, and withdrawal from the job. Journal of Applied Social Psychology,37(3): 457-477.

Vigoda, E. (2000). Internal politics in public administration systems: An empirical examination of itsrelationship with job congruence, organizational citizenship behavior, and in-role performance. Public Personnel Management, 29: 185-210.

Walumbwa, F. O., Cropanzano, R., and Goldman, B. M. (2011). How leader-member exchange influences effective work behaviors: social exchange and internal-external efficacy perspectives. Personnel Psychology, 64(3): 739-770.

Wang, D., Tsui, A.S., Zhang, Y. and Ma, L. (2003). "Employment relationships and firm performance, evidence from an emerging economy". Journal of Organizational Behavior, 24: 511-35.

Wayne, S. J., Shore, L. M., \& Liden, R. C. (1997). Perceived organizational support and leader-member exchange: A social exchange perspective. Academy of Management Journal, 40(1), 82-111.

Wayne, S. J., Shore, L. M., Bommer, W. H., and Tetrick, L. E. (2002). The role of fair treatment and rewards in perceptions of organizational support and leader-member exchange. Journal of Applied Psychology, 87: 590-598.

Weibel, A., Rost, K., and Osterloh, M. (2010). Pay for performance in the public sector? Benefits and (hidden) costs. Journal of Public Administration Research and Theory, 20: 387-412.

Williams, L. J., and Anderson, S. E. (1991). Job Satisfaction and Organizational Commitment as Predictors of Organizational Citizenship and In-Role Behaviors. Journal of Management, 91: 601-617.

Zhu, Y. (2016). Organization-based self-esteem affects employees' exchange relationship perceptions and extra-role behavior. Social Behavior and Personality, 44(3): 509-518. 